\title{
Factor XI deficiency and delayed hemorrhages after resection of choroid plexus papilloma: illustrative case
}

\author{
Cristina Mancarella, MD, ${ }^{1}$ Alessandra Marini, MD, ${ }^{1}$ Rocco Severino, MD, ${ }^{1}$ Paolo Missori, MD, ${ }^{2}$ Cristina Santoro, MD, ${ }^{3}$ and \\ Sergio Paolini, $\mathrm{MD}^{1,2}$
}

\begin{abstract}
${ }^{1}$ Department of Neurosurgery, IRCCS Neuromed, Pozzilli (IS), Italy; ${ }^{2}$ Department of Human Neurosciences, Sapienza University of Rome, Rome, Italy; and ${ }^{3}$ Hematology, Hemophilia and Thrombosis Center, University Hospital Policlinico Umberto I, Rome, Italy
\end{abstract}

\begin{abstract}
BACKGROUND Factor XI deficiency, also known as hemophilia $\mathrm{C}$, is a rare inherited bleeding disorder that may leave routine coagulation parameters within normal range. Depending on the mutation subtype, prolonged activated partial thromboplastin time may occasionally be found. The disease has an autosomal transmission, with an estimated prevalence in the general population of approximately 1 in 1 million. Heterozygosis accounts for partial deficits, but the tendency to bleed is unrelated to the measured activity of factor XI. Diagnosis usually follows unexpected hemorrhages occurring spontaneously or after trauma or surgical procedures.
\end{abstract}

OBSERVATIONS Few cases have been reported in the neurosurgical literature, all occurring spontaneously or after head trauma. Owing to its subtle features, the true incidence of the disease is probably underestimated. The authors report a case of a patient with previously undiagnosed factor XI deficiency who underwent uncomplicated resection of a fourth-ventricle papilloma and experienced delayed, severe hemorrhagic complications.

LESSONS The known association between choroid plexus tumors and intracranial bleeding raised differential diagnosis issues. This report may serve to help to investigate delayed hemorrhages after cranial surgery.

https://thejns.org/doi/abs/10.3171/CASE21333

KEYWORDS choroid plexus; delayed hemorrhage; hemophilia C

Factor XI (FXI) deficiency, also known as Rosenthal syndrome or hemophilia $\mathrm{C}$, is a rare, inherited bleeding disorder with a prevalence in the general population of approximately 1 in 1 million. ${ }^{1}$ Higher frequency has been found in some populations, such as Ashkenazi Jews and Iraqi Jews, who have a heterozygosis rate of $9 \%{ }^{2}$ The prevalence in the Italian population has been estimated to be approximately 1 in $1,000 .^{3}$

More than 190 mutations have been described involving the FXI gene, located on the long arm of chromosome $4 .{ }^{4} \mathrm{FXI}$ activity is usually below $15 \mathrm{lU} / \mathrm{dl}$ in homozygous forms and between 15 and $40 \mathrm{lU} / \mathrm{dl}$ in heterozygous forms. The occurrence of bleeding is unpredictable, however, and normally unrelated to the FXI clotting activity. ${ }^{5}$ Although prolonged activated partial thromboplastin time (APTT) may occasionally be found, most patients have normal coagulation parameters on routine laboratory tests. The suspicion is usually raised by unexpected bleeding occurring spontaneously or after trauma or surgical procedures. ${ }^{1}$ Few cases have been reported in the neurosurgical literature, all related to spontaneous hemorrhages and only sporadically to trauma. ${ }^{6-14}$ An association between FXI deficiency and intracranial hemorrhages after craniotomy procedures has not been documented so far. We report a case of undiagnosed FXI deficiency that manifested with delayed, severe hemorrhages after uncomplicated resection of a fourth-ventricle tumor.

\section{Illustrative Case}

A 63-year-old woman with a 10-day history of headache, gait disturbance, and dysmetria had a magnetic resonance imaging (MRI) diagnosis of a fourth-ventricle tumor causing obstructive hydrocephalus (Fig. 1). She had no personal or family history of bleeding. Routine preoperative test results, including coagulation parameters, were within normal range. The patient underwent surgery through a telovelar approach. A neoplasm mildly adherent to the floor of the fourth

ABBREVIATIONS APTT = activated partial thromboplastin time; $\mathrm{CT}=$ computed tomography; $\mathrm{F}=$ factor; $\mathrm{MRI}=$ magnetic resonance imaging INCLUDE WHEN CITING Published December 13, 2021; DOI: 10.3171/CASE21333.

SUBMITTED May 31, 2021. ACCEPTED September 9, 2021.

(C) 2021 The authors, CC BY-NC-ND 4.0 (http://creativecommons.org/licenses/by-nc-nd/4.0/). 

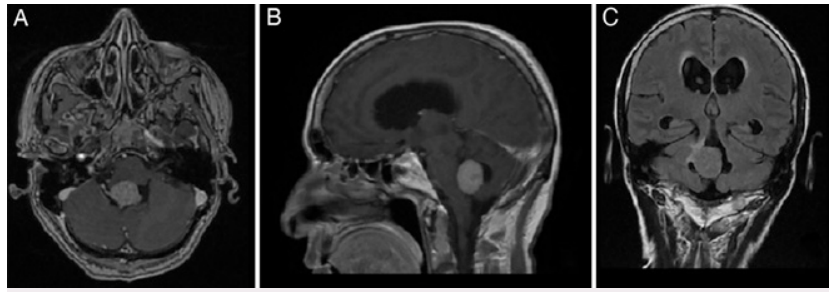

FIG. 1. Axial (A) and sagittal T1-weighted (B) and T2-weighted (C) MRI scans show a homogeneous contrast-enhancing mass of the fourth ventricle causing obstructive hydrocephalus.

ventricle was removed, and hemostasis was easily achieved. The first postoperative course was uneventful, and both computed tomography (CT) and MRI, performed at 24 and 48 hours, respectively, showed complete tumor resection without bleeding signs (Fig. 2A and B). Three days after surgery, the patient developed mild gait disturbance. CT showed a small blood clot within the fourth ventricle, with ventricular enlargement (Fig. 3A). Surgical removal of the clot and external ventricular drainage were performed with no complications and no neurological sequelae. The patient's postoperative CT scan was normal (Fig. 3B). Three days after the second operation, the patient showed drowsiness and confusion. CT showed a recurrent, large hemorrhage within the fourth ventricle (Fig. 4A). The patient underwent emergency surgery, and a thick clot mixed with swollen branches of the choroid plexus was removed. Her postoperative CT scan was satisfactory (Fig. 4B). The patient remained comatose, though responsive. Meanwhile, pathological examination yielded a diagnosis of choroid plexus papilloma. A literature search showed a clear association between choroid plexus tumors and intracranial hemorrhage, which was considered a possible explanation for such an unusual course. At the same time, hematological counseling was
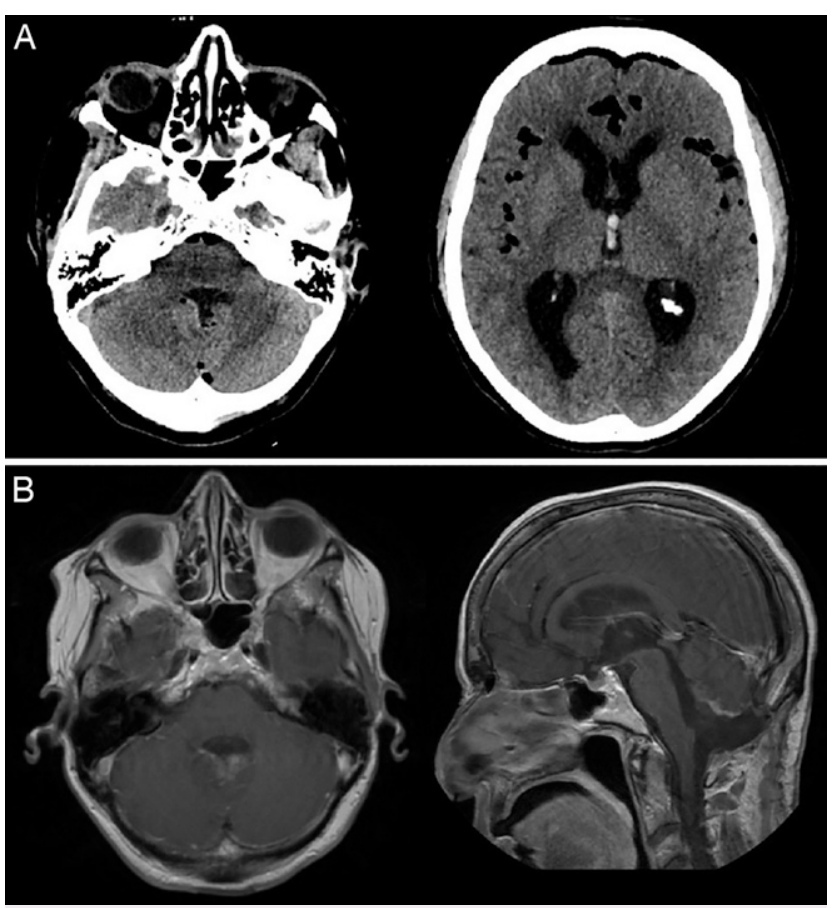

FIG. 2. Postoperative CT (A) and MRI (B) scans, obtained at 24 and 48 hours, respectively, show complete tumor resection.
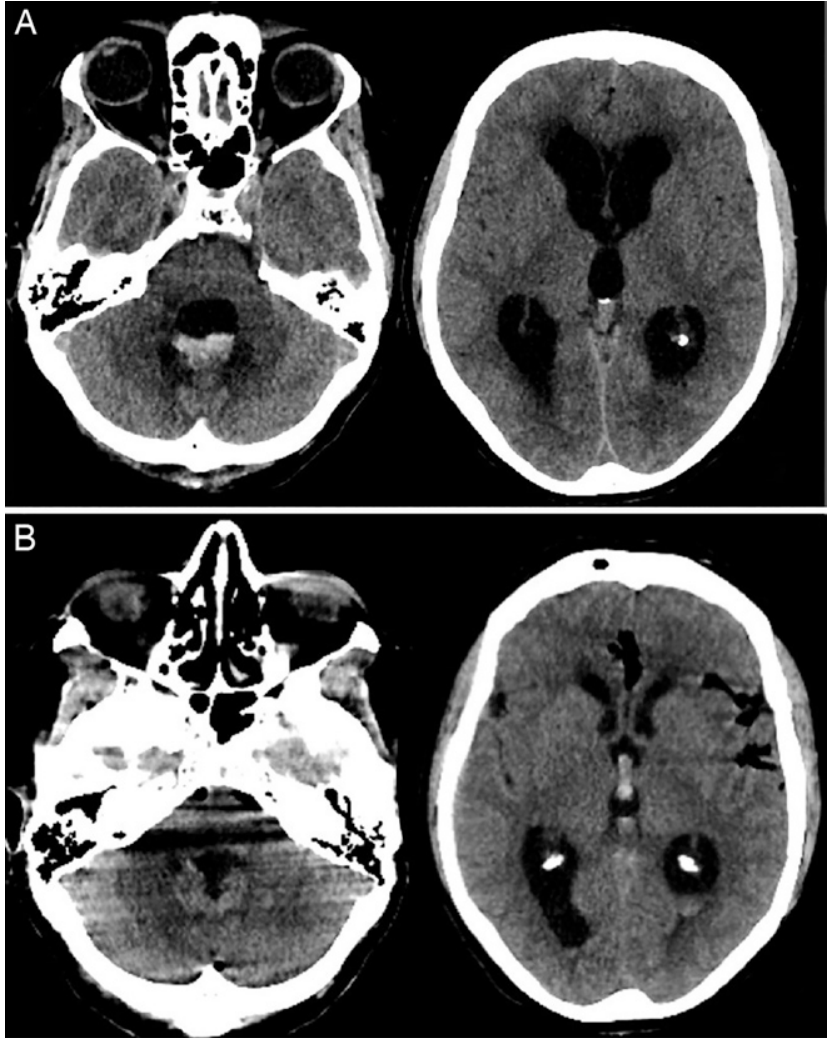

FIG. 3. Blood clot and ventricular dilatation shown on CT scans (A). Postoperative CT images $(B)$ reveal surgical removal of the clot.
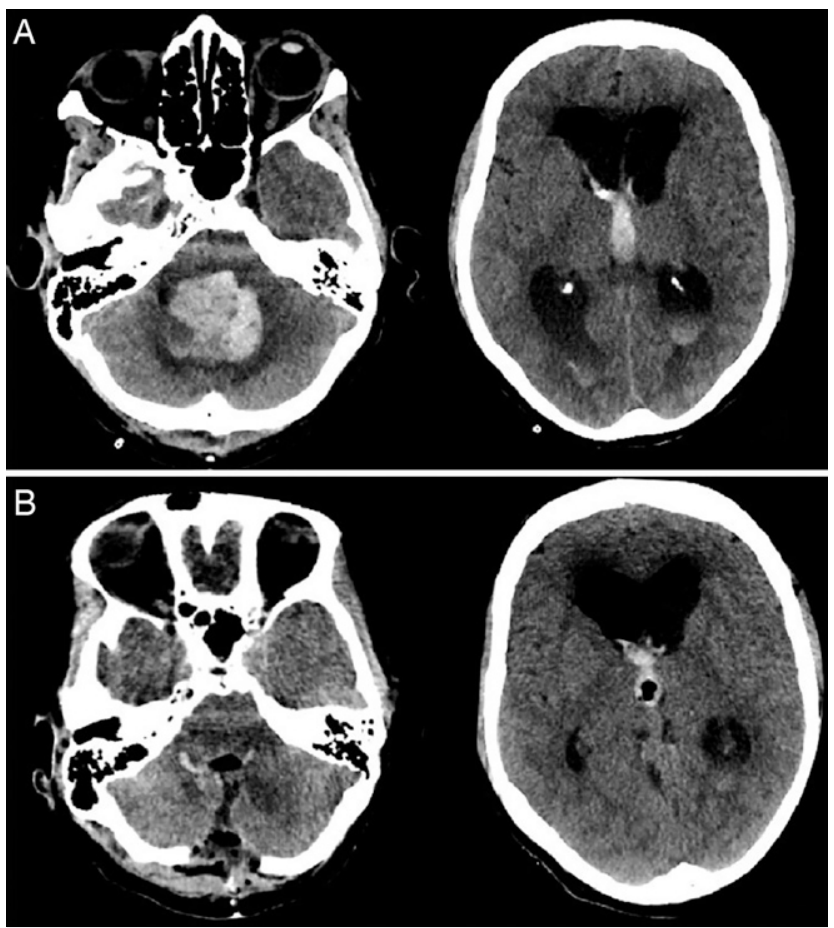

FIG. 4. CT scan (A) documented a large ventricle hemorrhage. Postoperative CT scan (B). 


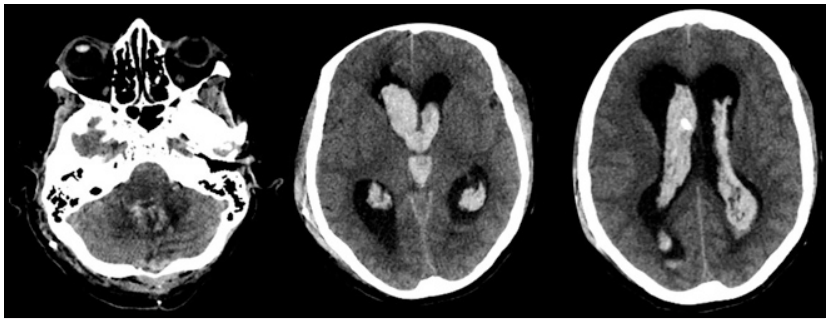

FIG. 5. CT scans showing hemorrhagic congestion of the choroid plexus.

requested, and further screening of coagulation parameters was started. In the following days, a CT scan showed further bleeding with severe hemorrhagic congestion of the supratentorial choroid plexuses (Fig. 5). Eventually, laboratory results documented a partial deficiency of FXI (34 IU/dl; normal range 70-120 IU/dl). The patient died 2 weeks later.

\section{Discussion \\ Observations}

To our knowledge, this is the first description of a post-craniotomy hemorrhage related to FXI deficiency. The disease is often undiagnosed. Depending on the mutation subtype, prolonged APTT may occasionally be found. ${ }^{15}$ Unexplained lengthening of APTT or history of bleeding, particularly in populations at risk, ${ }^{2,3}$ might justify specific screening for the disease. Prompt diagnosis might call for protective measures such as infusion of fresh frozen plasma, tranexamic acid, or FXI concentrate ${ }^{16,17}$ in preparation for elective surgical procedures. Unfortunately, most patients, including the reported case, have normal coagulation parameters, and the disease can only be suspected on a clinical basis.

The case we describe is extremely peculiar because not only the medical history and laboratory analysis but also the intraoperative findings did not suggest any coagulation disorder. Abnormal lengthening of the bleeding time, a clue for the diagnosis of a latent coagulopathy such as FXI deficiency, was not observed. Quite the contrary, intraoperative hemostasis was easily achieved and stable, as confirmed by a postoperative CT scan after each surgical procedure the patient underwent. Lacking signs of impaired hemostasis, attention was initially focused on the tumor histotype, being choroid plexus tumors reportedly associated with intracranial hemorrhages even spontaneous and distant from the tumor site. ${ }^{18-22}$ The third bleeding episode, which resembled hemorrhagic congestion of the choroid plexuses (Fig. 5), although calling for a search for hidden coagulopathies, reinforced the impression that the main problem could be a structural abnormality of the choroid plexus or a tumor-specific propensity for delayed bleeding, as also observed for other histotypes. ${ }^{23}$ In retrospect, we are inclined to believe that tumors known to be associated with postsurgical hemorrhages may act as a confounding factor for the diagnosis of underlying FXI deficiency. Nonetheless, in our case, the unfortunate coexistence of both factors cannot be excluded.

\section{Lessons}

FXI deficiency is a subtle bleeding disorder whose prevalence is probably underestimated. This report illustrates a possible pattern of presentation in neurosurgical practice. Normal intraoperative bleeding and uncomplicated hemostasis do not exclude the diagnosis. Recurring postoperative hemorrhages, even several days after surgery, should raise the suspicion and call for extended coagulation screening.

\section{References}

1. Santoro C, Di Mauro R, Baldacci E, et al. Bleeding phenotype and correlation with factor $\mathrm{XI}(\mathrm{FXI})$ activity in congenital $\mathrm{FXI}$ deficiency: results of a retrospective study from a single centre. Haemophilia. 2015;21(4):496-501.

2. Shpilberg $\mathrm{O}$, Peretz $\mathrm{H}$, Zivelin $\mathrm{A}$, et al. One of the two common mutations causing factor XI deficiency in Ashkenazi Jews (type II) is also prevalent in Iraqi Jews, who represent the ancient gene pool of Jews. Blood. 1995;85(2):429-432.

3. Zadra G, Asselta R, Tenchini ML, et al. Simultaneous genotyping of coagulation factor XI type II and type III mutations by multiplex realtime polymerase chain reaction to determine their prevalence in healthy and factor XI-deficient Italians. Haematologica. 2008; 93(5):715-721.

4. Asselta R, Paraboschi EM, Rimoldi V, et al. Exploring the global landscape of genetic variation in coagulation factor XI deficiency. Blood. 2017;130(4):e1-e6.

5. Peyvandi F, Palla R, Menegatti M, et al. Coagulation factor activity and clinical bleeding severity in rare bleeding disorders: results from the European Network of Rare Bleeding Disorders. J Thromb Haemost. 2012;10(4):615-621.

6. Henry El, Hoffman I, Rosenthal RL. Spontaneous hemorrhages caused by plasma-thromboplastin-antecedent deficiency; report of a case. J Am Med Assoc. 1956;162(8):727-729.

7. Vasileiadis I, El-Ali M, Nanas S, et al. First diagnosis of factor XI deficiency in a patient with subarachnoid haemorrhage. Blood Coagul Fibrinolysis. 2009;20(4):309-313.

8. Slade WR Jr, Rabiner AM. Plasma thromboplastin antecedent deficiency and subarachnoid hemorrhage. Angiology. 1973;24(9):533-537.

9. Lazzerini PE, Capecchi PL, Nizzi C, et al. Cerebellar haemorrhage, factor XI deficiency and concomitant risk factors. QJM. 2015; 108(10):829-831.

10. Siao D, Seetapah A, Ryman A, Guerin V, Mesli A, Maurette P. Optimal management of an aneurysmal subarachnoid hemorrhage in a patient with known factor XI deficiency: a case report. Clin Appl Thromb Hemost. 2008;14(1):108-111.

11. Brichant S, Vokaer M, Beukinga I, et al. Cerebellar hemorrhage due to factor XI deficiency. Cerebrovasc Dis. 2005;19(2):138-139.

12. Khealani B, Farhat Z, Mozaffar T. Factor XI deficiency-related spontaneous primary intraventricular hemorrhage. South Med J. 2000;93(10):1017-1018.

13. Alghamdi MA, Almubarak AO, Alsedrani N, Alshehri WM, Alturki AY. Pretruncal nonaneurysmal subarachnoid hemorrhage with underlying hemophilia C. World Neurosurg. 2019;127:109-112.

14. Espinosa-Rodríguez EE, López-Gutiérrez M, Tresserras-Giné G, Pesa-Vendrell N, Martínez-Pérez M. First case of delayed traumatic intracerebral hemorrhage in a patient with undiagnosed factor XI deficiency: diagnosis and management review. Brain Inj. 2020;34(11):1541-1547.

15. Emsley J, McEwan PA, Gailani D. Structure and function of factor XI. Blood. 2010;115(13):2569-2577.

16. Santoro C, Goldberg I, Bridey F, et al. Successful hip arthroplasty in an adult male with severe factor XI deficiency using Hemoleven $\AA$, a factor XI concentrate. Haemophilia. 2011;17(5):777-782.

17. Ince ME, Ozkan G, Ors N, Yildirim V. Perioperative anesthetic management in a patient with factor $\mathrm{XI}$ deficiency undergoing coronary artery bypass graft surgery. J Card Surg. 2020;35(6):1375-1379.

18. Ernsting J. Choroid plexus papilloma causing spontaneous subarachnoid haemorrhage. J Neurol Neurosurg Psychiatry. 1955;18(2):134-136.

19. Guan J, Liu G, Guo G, et al. Choroid plexus papillary carcinoma associated with hemorrhage. A case report. Neuroradiol J. 2006; 19(5):616-620. 
20. Maimone G, Ganau M, Nicassio N, Paterniti S. Paratrigonal choroid plexus papilloma presenting with satellite multiple supra- and infratentorial hemorrhages. Neuroanatomical basis and pathological hypothesis. Int J Surg Case Rep. 2013;4(3):239-242.

21. Matsushima M, Yamamoto T, Motomochi M, Ando K. Papilloma and venous angioma of the choroid plexus causing primary intraventricular hemorrhage. Report of two cases. J Neurosurg. 1973; 39(5):666-670.

22. Piguet $\mathrm{V}$, de Tribolet $\mathrm{N}$. Choroid plexus papilloma of the cerebellopontine angle presenting as a subarachnoid hemorrhage: case report. Neurosurgery. 1984;15(1):114-116.

23. Ren $\mathrm{X}-\mathrm{H}$, Chu $\mathrm{C}$, Zeng $\mathrm{C}$, et al. Delayed postoperative hemorrhage in 21 patients with intracranial epidermoid cysts. J Neurosurg. 2011;114(6):1592-1602.

\section{Disclosures}

The authors report no conflict of interest concerning the materials or methods used in this study or the findings specified in this paper.

\section{Author Contributions}

Conception and design: Severino, Paolini. Acquisition of data: Mancarella, Marini. Analysis and interpretation of data: Marini. Drafting the article: Mancarella. Critically revising the article: Missori, Santoro, Mancarella, Paolini. Reviewed submitted version of manuscript: Santoro, Paolini. Study supervision: Santoro.

\section{Correspondence}

Cristina Mancarella: IRCCS Neuromed, Pozzilli (IS), Italy. cristina. mancarella@gmail.com. 